\title{
The effect of living in the present time, healthy character development and social character growth of staff on their performance (Case Study: clinical and paraclinical areas of Ahwaz Imam Khomeini Hospital)
}

\author{
Farnaz Pishgar \\ Department OF MANAGEMENT (khorasgan) Branch , \\ Islamic Azad University, Isfahan, Iran \\ Corresponding Author: farnaz.pishgar2000@gmail.com>
}

\begin{abstract}
Keywords: The effect of living in the present, Healthy character development, Social character growth, Performance, Performance management
\end{abstract}

\begin{abstract}
The aim of the present research was to investigate the effect of living in the present, healthy character development and social character growth of staff on their performance in clinical and para-clinical fields of Ahvwaz Imam Khomeini hospital. In this research, the descriptive research method was of the correlational type. Necessary information was prepared from selected sample from the research statistical population, namely clinical and para-clinical staff of Ahwaz Imam Khomeini Hospital who was 1000 ones and 280 of them was selected as volume of the sample based on Cochran formula using available sampling. Data were collected using a researcherbuilt questionnaire based on Fordyce's 14-point model with 42 questions and performance questionnaire and Stephen E. Candrie performance questionnaire with 10 aspects and 32 questions. Cronbach alpha coefficient for questionnaire and performance questionnaire were 0.97 and 0.94 , respectively indicating acceptable reliability. Also, validity of the questionnaire was confirmed based on supervisors and number of experts in the field of management through content validity. Data analyses were done in to levels of descriptive and inferential statistics. In inferential part, regression analysis and Pearson correlation test were done using SPSS software. The results of the present study showed that living in the present, healthy character development and social character growth of Ahwaz Imam Khomeini Hospital staff have a positive effect on their performance and whatever staff live in the present and develop their character and be more social, their performance will increase.
\end{abstract}

\section{INTRODUCTION}

In today's world that efficiency has been increased in all fields, those organizations can remain that use their resources in best possible way and have the greatest efficiency. One of important organizational sources is manpower. Unsuccessful organizations lack the necessary efficiency to improve their labor productivity (Sheldon, 2004). So it can be said that the survival of activity of organizations depends on their staff performance. In fact, the performance is efficiency of personnel according to the legal determined obligations and states the amount of effort and boundaries of success in carrying out the job tasks and expected behavioral duties and a large amount of investments is done in different organizations to enhance the performance of employees (Hassani, 2014). Hence, today more than ever, organizations need to differentiate themselves through their intangible assets. Every year managers may spend weeks or even months of their time to develop their own organization's strategy to maintain a competitive advantage. In recent years, psychology has observed the emergence of a new approach called positive psychology that instead of dealing with injuries or mental disorders considers talents, abilities, skills, and generally positive aspects of human existence (Sheldon, 2004). Research has shown that positivistic human resources and mental assets of organization are very effective to improve organizational performance (Luthans et al., 2007) so that the willingness and readiness of individuals for improving and developing increase and, ultimately, their performance can be developed (Yazdanshenas, 2014). 
Living in the present, healthy character development, and social character growth are of the components of positivistic psychology in people which they themselves are the cause of happiness in the workplace. Happiness is a positive feeling that comes from a sense of satisfaction and victory and it is one of the basic needs of life and a factor for growth and success (Niaz Azari, 2014). Jan Rich (2002) also believes that happiness is not just to know that good things will happen in your life, but your awareness to this issue that you are causing these accidents. The lowest level of happiness is the knowing the fact that you can prevent bad accidents. This sense of domminance and control over the good and bad things of life altogether creates a good impression on you (Baseri, 2010). Living in the present, healthy character development, and social personality growth lead to happiness in people, which ultimately lead to a positive attitude to life, positive self-concept, having a mental health and emotional balance, hope for the future, good attitude and satisfaction of own self and others, balanced social relations, avoiding hatred, consciously choosing life goals, efforts to achieve the goals, avoiding waste of time and laziness, increased success in life, having a high indices of life, better functioning of immune system against stress, better sleep, more willing to help others and making better decisions (Sharifi et al., 2010). The importance of considering happiness and factors creating it in organizations arises from where happiness from one side increases positive emotions of staff and on the other hand by reducing negative emotions, will increase productivity (Fani and Aghaziarati, 2013). Accordingly, it is important to consider this issue in macro policies. Having employees with a healthy and social character is of the ideals of the organizational and industrial complexes. One of the most sensitive organizations that organizational performance of its employees plays an essential role in the health and life of the community is hospitals. This study aims to investigate the influences of life in the present, healthy character development, staff social personality development on their performance.

\section{VARIABLES OF THE STUDY}

\section{Live in the present:}

People who live in the present time always pay attention to the present time and try to take maximum pleasure from everyday activities. Happy people enjoy their life more than unhappy people, because they do not involve their mind to understand the bitter events of the past and they do not and upset about days that are not yet come (Lama, 2001:46).

\section{Healthy character development:}

The basic principles of mental health include loving self, self-acceptance, self-discovery and selfhelp and the existence of happiness in life depends on the right decision. Human can decide correctly when recognizes own self and determines whether he/she has the ability to implement that decision successfully or not (Lama, 2001: 46).

\section{Social and extrovert character development:}

Those people are happier who enjoy an active social life, so Fordyce knows extroversion and sociability as the most important ways to the reach happiness (Lama, 2001: 46). 


\section{Conceptual model of the research}

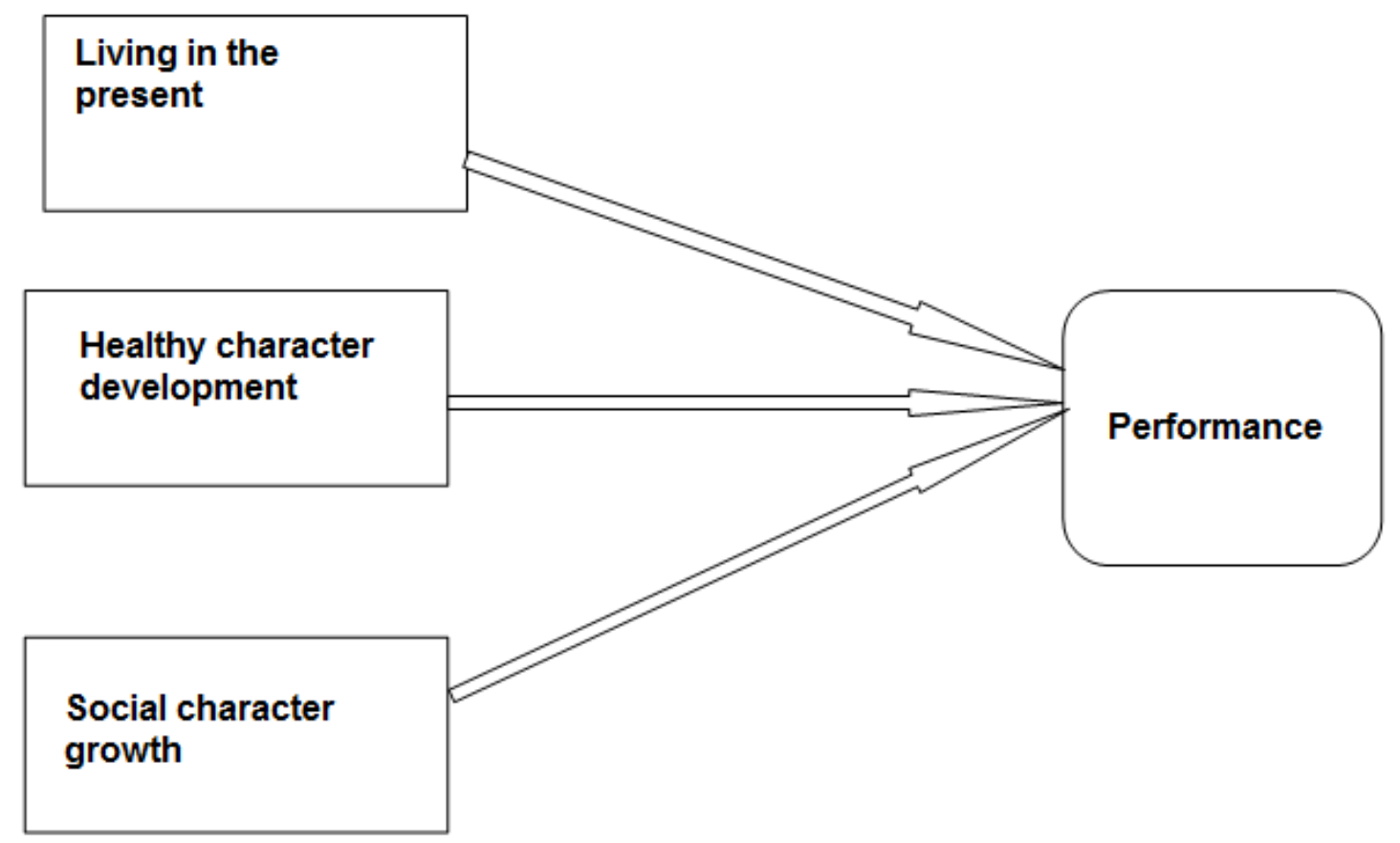

\section{METHOD}

This research is descriptive of the correlational type. The statistical population of the present research is all clinical and para-clinical staff in Ahwaz Imam Khomeini Hospital that according to the selection statistics of Hospital they were 1000 persons. 280 of them were studied based on Cochran formula. In this study, two questionnaires were used to collect data and information. The first questionnaire investigated the effect of living in the present, healthy character development, and social character growth among staff. This questionnaire was prepared based on 5-point Likert scale (very low, low, medium, high, and very high). The lowest and the highest score for items of questionnaire was 1 and 5, respectively. A high score in each aspect shows higher mentioned aspect among staff. Staff performance questionnaire evaluated 10 dimensions using 32 questions. Each question had three options (beyond expected, as expected, needs improvement). In each question, the score for selection of "beyond expected", "as expected", and "needs improvement" was 3, 2, and 1 respectively. If staff score was 64 to 96, their performance was "beyond expected"; if staff score was 32 to 64, their performance was "as expected"; if staff score was lower than 32, their performance needed programming for improvement. In this study, face and content validity were used to investigate the validity of questionnaires. Therefore, after developing the questionnaire, each of questions was investigated by experts for the purpose of determining connection of items with the variable under assessment. After doing investigations, improper and obscure items were eliminated or moderated. The validity assessment or repeatability of questionnaire items also done using Cronbach alpha that it was for questionnaire of components 0.973 and 0.945 for performance questionnaire indicating acceptable validity of the research questionnaire. The method of information analysis in this research is both descriptive and inferential. Average descriptive statistics, standard deviation, frequency, and percentage were used in descriptive section of data and information analysis. Regression analysis and Pearson correlation test using SPSS software were used in inferential section. 


\section{FINDINGS}

\section{Demographic description:}

$59 \%$ of respondents were women with the frequency of 166 and $41 \%$ of them were men with the frequency of $114.70 \%$ of respondents were married with the frequency of 196 and $30 \%$ of them were single with the frequency of 84 . The highest percentage and frequency was related to people with Bachelor of Science (118 persons with $42.1 \%$ of statistical population) and the lowest percentage and frequency was related to people with Master of Science (29 persons with $10.4 \%$ of statistical population) and diploma (28 persons with $10 \%$ of statistical population).

Table 1. Descriptive indices of components studied in this research

\begin{tabular}{|c|c|c|c|c|c|}
\hline & Number & Minimum & Maximum & Average & $\begin{array}{c}\text { Standard } \\
\text { deviation }\end{array}$ \\
\hline Living in the present & 280 & 3 & 14 & 10.80 & 2.698 \\
\hline $\begin{array}{c}\text { Healthy character } \\
\text { development }\end{array}$ & 280 & 5 & 15 & 11.69 & 2.296 \\
\hline Social character growth & 280 & 3 & 14 & 10.60 & 2.690 \\
\hline
\end{tabular}

As can be seen in Table 1, average scores of staff in aspects of living in the present, healthy character development, and social character growth are 10.80,11.69, and 10.60, respectively.

\section{Describing performance and its aspects}

Data obtained from staff performance questionnaire in Ahwaz Imam Khomeini Hospital determined based on 3 options of "beyond expected", "as expected", and "needs improvement" are given in Table 2.

Table 2. Distribution of respondents in terms of total performance

\begin{tabular}{|c|c|c|c|c|}
\hline & Frequency & Percentage & Percentage of validity & The cumulative percentage \\
\hline As expected & 3 & 1.1 & 1.1 & 1.1 \\
\hline $\begin{array}{c}\text { Beyond } \\
\text { expected }\end{array}$ & 277 & 98.9 & 98.9 & 100.1 \\
\hline Total & 280 & 100.0 & 100.0 & \\
\hline
\end{tabular}

As shown in Table 2, total performance of $99 \%$ of respondents with frequency of 277 was "beyond expected" and total performance of $1 \%$ with frequency of 3 was "as expected".

Table 3. Descriptive indices of performance

\begin{tabular}{|c|c|c|c|c|c|}
\hline & Number & Minimum & Maximum & Average & Standard deviation \\
\hline Total performance & 280 & 32 & 156 & 135.78 & 15.177 \\
\hline
\end{tabular}

As it is clear from Table 3, the average of total performance with frequency of 280 was 135.78 .

\section{Inferential findings}

In this section, at first, the normality of the distribution of variables under investigation is evaluated using normality test to use parametric and non-parametric tests for investigating study hypotheses.

\section{Kolmogorov-Smirnov test}

Kolmogorov-Smirnov test is used to investigate normality. In this test, the normality of distribution of variables is investigated at level of 0.05 . The rejection of initial hypothesis means the rejection of the normality of distribution of variables. 
Table 4. Investigating the normality of staff performance and its components

\begin{tabular}{|c|c|c|c|c|c|}
\hline & Number & Average & $\begin{array}{c}\text { Standard } \\
\text { deviation }\end{array}$ & Statistics & p-value \\
\hline Living in the present & 280 & 10.80 & 2.698 & 3.396 & 0.064 \\
\hline $\begin{array}{c}\text { Healthy character } \\
\text { development }\end{array}$ & 280 & 11.69 & 2.297 & 3.834 & 0.061 \\
\hline Social character growth & 280 & 10.60 & 2.690 & 3.819 & 0.058 \\
\hline Total performance & 280 & 135.78 & 15.177 & 3.413 & 0.074 \\
\hline
\end{tabular}

According to Table 4, p-value obtained for components of living in the present, healthy character development, and social character growth and also the staff performance was obtained higher than 0.05 and consequently, initial hypothesis is not rejected at level of 0.05 . Therefore, the distribution of components and also staff performance are normal.

\section{Pearson correlation test}

Pearson correlation test was used to investigate the relationship between two variables. In this test, initial $\left(\mathrm{H}_{0}\right)$ and opposite $\left(\mathrm{H}_{1}\right)$ hypotheses are as follows:

$$
\left\{\begin{array}{l}
\mathrm{H}_{0}: \rho=0 \\
\mathrm{H}_{1}: \rho \neq 0
\end{array}\right.
$$

In which, $\rho$ indicates the correlation between two variables. In this test, if initial hypothesis is rejected it can be concluded that two variables has a significant relationship.

Hypothesis 1: there is a relationship between staff living in the present and their performance.

Table 5. Investigating the relationship between living in the present and total performance

\begin{tabular}{|c|c|}
\hline Total performance & \\
\hline 0.332 & Pearson correlation coefficient \\
\hline 0.000 & p-value of living in the present \\
\hline 280 & Number \\
\hline
\end{tabular}

According to Table 5, it can be seen that p-value has obtained lower than 0.05 ; therefore initial hypothesis is rejected at level of 0.05 . Consequently, there is a significant positive relationship between living in the present of Ahwaz Imam Khomeini Hospital staffs and their performance. It means their performance has been increased with enhancement of living in the present.

\section{Hypothesis 2: there is a relationship between staff healthy character development and their performance.}

Table 6. Investigating the relationship between healthy character and total performance

\begin{tabular}{|c|c|}
\hline Total performance & \\
\hline 0.422 & Pearson correlation coefficient \\
\hline 0.000 & p-value of healthy character \\
\hline 280 & Number \\
\hline
\end{tabular}

According to Table 6 , it can be seen that p-value has obtained lower than 0.05 ; therefore initial hypothesis is rejected at level of 0.05 . Consequently, there is a significant positive relationship between healthy character development of Ahwaz Imam Khomeini Hospital staffs and their performance. It means their performance has been increased with enhancement of healthy character development. 


\section{Hypothesis 3: there is a relationship between staff social character and their performance.}

Table 7. Investigating the relationship between social character and total performance

\begin{tabular}{|c|c|}
\hline Total performance & \\
\hline 0.478 & Pearson correlation coefficient \\
\hline 0.000 & p-value of social character \\
\hline 280 & Number \\
\hline
\end{tabular}

According to the above Table, it can be seen that p-value has obtained lower than 0.05 ; therefore initial hypothesis is rejected at level of 0.05 . Consequently, there is a significant positive relationship between social character of Ahwaz Imam Khomeini Hospital staffs and their performance. It means their performance has been increased with enhancement of social character.

\section{DISCUSSION AND CONCLUSION:}

This research was done to investigate the effects of living in the present, healthy character development, and social character growth of staff in clinical and para-clinical fields of Ahwaz Imam Khomeini Hospital on their performance. 280 staff of this hospital was studied. The results of the present research showed that there is a significant positive relationship between staff increased living in the present and their performance $(\mathrm{r}=0.332, \mathrm{p}<0.05)$. Therefore, there is a significant positive relationship between living in the present of Ahwaz Imam Khomeini Hospital staff and their performance. It means their performance has been increased with enhancement of living in the present. In this field, a direct research was not found for the comparison purpose. The results of the present research showed that there is a significant positive relationship between staff healthy character development and their performance $(\mathrm{r}=0.422, \mathrm{p}<0.05)$. Therefore, there is a significant positive relationship between healthy character development of Ahwaz Imam Khomeini Hospital staff and their performance. Undoubtedly, a healthy person can be considered as a person with communicational skills and constructive interactions and this is related to personal communicational skills and attention of managers to communications and training communicational skills among them can have a positive effect on performance. The results of the present research showed that there is a significant positive relationship between staff increased social character development and their performance $(r=0.478, p<0.05)$. Therefore, there is a significant positive relationship between social character development of Ahwaz Imam Khomeini Hospital staff and their performance. It means their performance has been increased with enhancement of social character development. The results of studies such as Sattari (2013) has shown that persons whose social character grows pays attention to constructive communications in workplace and can create an environment free from stress at work. This can have a direct and positive effect on both their own performance and efficiency and performance and efficiency of colleagues. Aggregately, the results of the present study showed that staff performance is improved with enhancement of living in the present, healthy character development, and social character growth. Thus, it is suggested that management orients staff toward obtaining results in the present time works with an emphasis on implementing daily organizational programs. It is proposed that staff actively participate in growth and education courses. Also, it is suggested that communicational canal between staff is developed clearly and informal communicational networks in the organization are facilitated and encouraged. The researchers, however, conducted their research with some restrictions, such as access to the today results of the world, distributing and collecting questionnaires, and etc, but research restrictions can merely be known as the possibility of generalizing the results and findings of this research to other organizations, especially hospitals. This study was done through a quantitative method and using a questionnaire. It is recommended that a research with qualitative approach to be conducted through interviews with employees and the results are compared with results of the present study. In this study, only workers in the clinical and preclinical fields of Ahwaz Imam Khomeini Hospital were studied. It is suggested that a research to be conducted more broadly in hospitals in Ahwaz and other cities of the country. Such a research also be performed in other 
public and private organizations in the country and the results are compared with results of the current study.

\section{References}

[1] Baseri, A, (2010), The role of happiness and hilarity development in enhancement of epic spirit, Journal of Military Psychology.

[2] Fani, A. A., Aghaziarati, M., (2013), identification of individual happiness and organizational components and the assessment of these components. Management of organizational culture, 11 (1), pp. 69-86.

[3] Jazani, N., (2008), The management of human sources, Nei Publication, $2^{\text {nd }}$ Edition, Tehran.

[4] Hassani (2014), the role of organizational learning in accountability and job performance of health staff, Orumieh Journal of Nursing and Midwifery faculty, 12 (10), pp. 988-996.

[5] Luma, D., Katler, H.C., (2003), the art of happiness, translated by Rafiee, $2^{\text {nd }}$ Edition, Tehran: Tandis Bookstore.

[6] Niaz Azari, Q. (2014), Effects of freshness and hilarity on the progress of high school students in Sari. 2 (3), pp. 35-57.

[7] Pahlevan Sadegh, A, Bakhtiar Nasrabadi, H.A., (2009), Educating the Fordyce's happiness model and its effect on enhancement of happiness in Martyrs and Veterans families, Journal of Behavior, $16^{\text {th }}$ year, No. 84, pp. 35-46.

[8] Sharifi Kh, Souki Z., Tagharrobi, Z., Akbari H., (2010), The status of hilarity and its related factors among students of Kashan University of Medical Sciences, during 2006-2007, 14(1), pp. 62-69.

[9] Tripi, M.M., (2005), The necessity of creating hilarity in organizations, translated by Rezaei, Ahmad Ali, Journal of Management, No. 105-106.

[10] Zarei, M.H., Jandaghi, Gh., Haghgouyan, Z., (2009), Recognizing the hilarity components in workplace and assessing the status of these components in executive organizations in Qom province, Governmental Management, 1(2), pp. 35-48.

[11] Zahedi, Sh., Rafiee, M., (2011), Investigating the relationship between human resource strategy and ethical decision making strategy with organizational performance: a research in research organization of Ministry of Agriculture, General Management Research, 4(13), pp. $5-24$.

[12] Yazdanshenas, M., Khoshnoud, A.,(2014), Determining the pattern of relationships between knowledge sharing and organizational citizenship behavior based on the concepts of positivistic organizational behavior. Management faculty of Tehran University, 6 (1), pp. 189208. 